Journal of the British Society for Phenomenology, Vol. 38, No. 2, May 2007

\title{
RE-ENCHANTING NATURE: HUMAN AND ANIMAL LIFE IN LATER MERLEAU-PONTY TRISTAN MOYLE
}

The notes from three courses on the concept of nature given by MerleauPonty at the Collège de France from 1956 until 1960 have recently been translated. ${ }^{1}$ The first two courses come to us in the form of notes taken by a student who attended Merleau-Ponty's lectures; the third course consists in a series of personal notes written by Merleau-Ponty himself. Although all three courses must therefore be used with caution, they nonetheless are important for at least two reasons: they offer an insight into the broader scope of The Visible and the Invisible, and they provide the outline of a solution to a problem regarding the relation between animal and human life that arises after the work of Heidegger and McDowell. The problem can be formulated as follows: Heidegger and McDowell both make use of the idea of second nature to overturn the untenable split within human nature that ensues from the traditional conception of reason as a qualitative difference 'added' to nature. Unfortunately, by extending the 'space of reason' into this reconceived idea of nature the metaphysical split within human nature simply re-emerges between humans and other animals. Despite the positive interpretation of animal life taken from the theoretical biologist Jacob von Uexküll, to whom both Heidegger and McDowell turn, the concept of nature no longer provides the support required for justifying the belief that humans and animals share a specifically natural existence. The difficulty is to articulate a sense of sameness without falling back into the traditional, factorising conception of something generically given to which a specific difference is added. I will argue that Merleau-Ponty provides a solution in The Visible and the Invisible and in the recently translated lecture courses on the concept of nature by offering a more radical re-enchantment of both human second nature and animal nature, centred on the aesthetic concept of style.

I

Throughout his philosophical life Heidegger criticises the form of traditional philosophical anthropology that determines man as a rational animal. This determination arises, Heidegger suggests, not simply because of the translation of the Greek definition of man as 'something living which has reason' into Latin but because this translation carries within it a metaphysical interpretation. Whilst not completely false, the interpretation covers over the basis for the Greek definition; with the rise of Roman humanism, man is 
abandoned to the realm of animalitas as one living being amongst others in contrast to plants, animals and God. ${ }^{2}$ Though animals and plants may be subordinated to the human being in light of his possession of the qualitative difference of reason nonetheless, Heidegger suggests, the human being's character as an organism remains decisive. With this form of philosophical anthropology one ends up with a composite entity, with one foot in a natural, animal world and one foot in a supernatural domain of reason. Yet the ontological relation between these two sides of human nature, how exactly they come together, remains vague and mysterious. ${ }^{3}$

McDowell, more recently, has also argued that traditional conceptions of the human being as an 'animal endowed with reason' pose the threat of a deeply unsatisfactory metaphysical split within our nature. ${ }^{4}$ Unlike Heidegger, who locates the source of this metaphysical split at least as far back as the rise of the Roman world, McDowell suggests that the distortion undergone by the Greek definition of man can be traced to the 17th century scientific revolution. The rise of science within the modern age has contributed to a disenchantment of our conception of nature; nature is increasingly determined as a system of impersonal, physical forces whose reality is described exclusively by modern mathematical physics. The incipient split within a unified conception of the human being is at this moment thrown wide open: it becomes increasingly difficult to see how our capacity to give and receive reasons can be accommodated within the law-like realm of nature described in this way by science. A metaphysical split between the 'rational' and 'animal' components of the human being follows and reason is placed within, as McDowell puts it, a supernatural 'space of reason'.

Even if McDowell and Heidegger differ on the historical moment when the basis of the Greek definition of man gets distorted, nonetheless both agree on the problems that ensue from this distortion and both, more importantly, agree on the way to overcome them. Given McDowell's contention that Aristotle was innocent of the dualism that later befell the conception of man as a rational animal, he argues for a return to the specifically Aristotelian idea that normal, mature human beings are rational animals (MW, Lecture IV). This argument is pursued by focusing on the conception of practical wisdom within Aristotle's Nicomachean Ethics (MW81). McDowell suggests that the conception of second nature, used by Aristotle to describe the ethical upbringing that instils an appropriately shaped state of the practical intellect, can be generalised to include the whole of human thinking. Thus a normal part of coming to maturity includes being initiated into a repertoire of conceptual capacities and, thereby, letting one's eyes be opened to the demands of reason that are 'already there'. By taking on board the requirements of reason characteristic of an adult human being we actualise ourselves as the animals that we are: our habits of thought and action become second nature (MW125). 
This conception of second nature, McDowell suggests, partially 're-enchants' the idea of nature bequeathed by scientific naturalism.

The McDowellian conception of second nature is described by Heidegger in Being and Time as the human being's understanding of Being. Our understanding of Being is, as Heidegger puts it, 'already-there'; human existence is thrown in the midst of beings, into a world or linguistic tradition that has already been disclosed. As such Being-in-the-World entails Being-in as a structural component of human existence; it represents what Heidegger calls our facticity. The ramifications of this conception of experience are manifest in the theory of perception offered by both early Heidegger and McDowell. As Heidegger suggests, we do not hear pure noise or take on board bare sense-impressions and then interpret these data. We directly perceive the things themselves: we hear " $\ldots$ the column on the march, the north wind, the woodpecker tapping..." (BT207). If that things are thus and so is the content of an experience, and of a judgement if a subject takes the experience at face value, then this very same content, that things are thus and so, is also according to McDowell and early Heidegger what we take in from the world (MW26). The things themselves are in this case perceptible facts, aspects of the layout of reality: how things are. Heidegger names facts 'significations' (BT204); worldly items which are already there, deposited and articulated into a totality of significance by the understanding of Being into which we are thrown. The concept of a linguistic tradition plays a similar role in McDowell (MW125). This kind of perceptual taking-in of already conceptually structured content was barred from the picture of experience that involved a divorce between our nature, including crucially our natural capacity for reception through the bodily organs of sense, and our rationality. On the traditional picture we can take on board only those non-conceptual data that causally impact upon us: bare sense-impressions and the like. On the conception of experience advocated by early Heidegger and McDowell our second nature or understanding of Being constitutes the world that is already there when our operations of receptivity come into play. Initiation into the repertoire of concepts possessed by the linguistic community opens our eyes to this conceptually structured world into which we are thrown.

This transcendental use made of the concept of second nature goes some way to resolving the problem of metaphysical dualism. The 'space of reasons' extends outwards to include part of our idea of the natural world that had previously been handed over to scientific naturalism. As McDowell puts it, we are animals whose natural being is itself permeated with rationality (MW85). Reason is not a specific difference 'added on' to our animality: we cannot strip off what is special to us and recognise the non-conceptual residue as what figures in the perceptual lives of animals, as a sort of isolated lowest common denominator that we share with them (MW64). McDowell and Heidegger each 
in their own way dismiss the idea that we share perceptual, world-representing core content at some level with other animals. The content we take in through our 'natural', corporeal capacity for sense perception is, from the ground up, thoroughly conceptual. This idea allows them to overturn the metaphysical split within human nature. However, an important insight contained within the flawed conception of traditional philosophical anthropology is that, at the expense of dualism, it is at least evident in what way the human being, as a naturally existing thing, is related to other animals. With one foot in the natural domain of animalitas, we enjoy perceptual experience of the same world as other living things - at least with those animals that possess similar corporeal sense organs to ourselves. However, in the revised picture the truth contained within this insight is unfortunately lost; we are no longer thought to share a common content with other animals to which is 'added' a specific difference. In perceptual experience we take in conceptual content; our second nature or world, broadly speaking, is riven with a congealed form of spontaneity. Yet this is wholly unsatisfactory; there appears to be nothing intelligibly natural about this kind of receptivity, nor is it any longer obvious what we share within experience with non-human animals. The price of overcoming the metaphysical split between nature and reason within the human being appears to be its re-emergence between human beings (reason) and other animals (nature).

Heidegger himself seems well aware of this; it is a thought that is captured in an expression he often uses: 'the animal is poor in world'. This expression is given its most comprehensive analysis by Heidegger in his 1929-30 lecture course The Fundamental Concepts of Metaphysics. This course, in its comparative analysis of the world of man and the environment of the animal, is supposed to complement the phenomenology of our everyday world given in Being and Time and the history of the concept of world given in the lecture On the Essence of Ground. ${ }^{5}$ The expression 'The animal is poor in world', Heidegger argues, does not entail that the animal has less in respect to what is accessible to it, that the difference between the world of man and the world of the animal is simply one of degree in the range and penetrability of things. Nor does the expression mean that the difference is one of quality: that the animal takes what is given to it from the world differently from how the human being takes what is given to it from the world. In other words, it is not, Heidegger claims, as if humans and animals stand over against a wall of beings with the same shared content (FCM278).

Rather, to say that the animal is 'poor in world' entails that animals cannot attend to the manifestness of beings; animals do not have access to the world that is disclosed for us. On the other hand, the animal is not like the stone: that is to say, entirely worldless. Animals have access to something that actually is - the nest that is sought out, the prey that is seized - it is just that they cannot 
experience these things as beings. In order to flesh out the curious intermediary position of animal life between the worldlessness of material things and the worldly existence of man Heidegger draws upon theoretical biology, including the work of J. von Uexküll.

Uexküll belongs to the tradition of developmental or morphogenetic biology that also includes von Baer and Driesch, both of whom are also discussed by Heidegger. The distinctive trait of this trend in biology is a refusal to explain the category of life in physical or chemical terms, seeking instead to expose unique sources of biological order on the basis of a dynamic, generative field within which the organisation of the egg or organism takes place. According to dynamic morphology, closely related to embryology, this field provides the context and structure for patterns of development to emerge. Uexküll's developmental approach to biology runs in tandem with his work in ethology, the study of animal behaviour, carried out in his Institute for the Study of the Environment founded in 1926. The distinctive characteristic of Uexküll's work in this area is his attempt to reconstruct the particular environment of an animal through morphological and physiological analysis. The world is not conceived as present-at-hand independently of the animal: it is there for it on the basis of the number, quality and distribution of its various sense-organs and the condition of its nervous system. Consequently, each animal species has its own distinctive environment. The explicit target of this Uexküllian-inspired biology is the Darwinian assumption of a present-at-hand organism face to face with an unmediated and given present-at-hand environment. The organism on this Darwinian picture is conceived as passively adapting itself to selective pressures from an independent and selfsubsisting external world. Against this, Uexküll's conception of an internal relation between animal and world entails an adaptation of the environment into the organism. As Merleau-Ponty later points out, there is in Uexküll the idea of a 'tolerance' of animal forms rather than a brute battle for survival. As such, if biology is to retain the idea of fitness values after Uexküll's critique of Darwinian ecology - as it surely must - this can no longer mean fittedness to an independent environment but rather the differential repetition of entire life cycles, in which both the organism and the environment are implicated. ${ }^{6}$

Ultimately, Uexküll believed that the empirical science of comparative anatomy would be able to offer insights into the inner and outer worlds of a particular organism given the nature of the relation between its bodily form and the unique world it inhabits. He explicitly conceived his approach as a reworking of Kant's transcendental aesthetic: the distribution of the senseorgans, as well as the perceptual and behavioural relation of the animal to its particular environment, is regulated by what he calls a 'building plan'. This 'building plan' is a kind of a priori spatial and temporal field unique to each animal species. ${ }^{7}$ Through empirical investigation of the behaviour and 
anatomical structure of an animal, Uexküll believed it was possible to acquire insights into the underlying 'building plan' that animates that animal's life.

Heidegger, perhaps understandably, ignores the ambitions Uexküll holds for comparative anatomy. Indeed, Heidegger explicitly criticises the idea that one can gain insight into the life of a glow-worm by producing a copy of its retinal image, a technique that Uexküll appears tempted to employ in some of his writings. Heidegger's goal on the contrary is to work out a philosophical interpretation of the organism on the basis of Uexküll's concrete scientific investigations (FCM263). The key term in this context is the idea of an environment. The animal organism is constituted by inter-related drives, for example, the drive to forage, hunt, escape and protect offspring. These interrelated drives make up what Heidegger calls an 'encircling ring'; the animal is 'open to' those things within the ring - for example, sources of nourishment, holes, predators - that disinhibit or release its drives. Thus the instinctual activity of an animal is not located within some kind of interiority that subsequently adapts itself to an external, given environment. Rather, the encircling ring of inter-related drives that makes up the animal organism is already 'out there', opening up an environment within which the animal can relate itself to things. This, Heidegger suggests, entails that animal behaviour is not to be conceived mechanistically, as a series of events or a process. An animal is not related to its environment through a series of external stimuli inducing a chain of atomic, localised reflexes strung together like beads on a piece of string. Rather 'stimuli' are disclosed on the basis of a unity of possible behaviour regulated by the circle of drives comprising the horizon of that animal's particular environment. Animals are, in this sense, semantic engines: rather than merely processing information in a sub-personal way, they also become informed of content-involving features of their environment. ${ }^{8}$ There is between the animal and objects within its environment an internal relation: the worm behaves as if fleeing in a particular way with respect to the mole, the bird behaves as if seeking out its nest. The difference between the behaviour of an animal and the action of a human being is that the animal is captivated by the things that disinhibit its drives. This is what Heidegger calls the eliminative character of animal behaviour; animals are only 'open for' those aspects of things immediately pertinent to the release or satiation of a particular drive. The animal is as such entirely absorbed within its environment.

Despite the positive interpretation of the animal organism in terms of its encircling ring, nonetheless Heidegger repeatedly emphasises that the animal is separated from man by an abyss (FCM264). ${ }^{9}$ The reason for this is that the concept of world is intended in a strong sense, it involves awareness of self, the possibility of objective experience, that is the capacity to experience beings as beings, and, above all, the possession of language (FCM274). Given that on 
early Heidegger's conception of perceptual experience even a minimal taking on board of empirical content from the world requires these elements, then the animal must be excluded from the human domain. Hence, Heidegger's claim that an abyss separates the human world and the animal environment. McDowell, like Heidegger, also intends the concept of world in a strong sense: it must include the conceptual content we associate with the understanding, from the ground up. In order to short-circuit the worry that animals are thereby determined as Cartesian automata McDowell, citing Gadamer, also makes use of Uexküll's conception of an animal's environment (MW115ff).

Nonetheless McDowell is more unwilling than Heidegger to follow through the consequences of separating the world of the human being from the environment of an animal. Whereas Heidegger rightly stresses the radical difference that opens up between man and animal on a revised conception of our perceptual experience, McDowell tries to hang on to a notion of our likeness to other animals. Thus, he suggests environment and world are two kinds or species of perceptual sensitivity (MW64). Yet the content of the genus that these species have in common is opaque: asserting that it is a 'plain fact' that we share perception with mere animals does not clear up the opacity (MW114). There appears to be after all nothing within experience that we share. At other times, McDowell suggests that we share our first nature with the lives of higher animals, for example, the concept of nurturing the young. These unassimilated residues of first nature persist in the transformation effected by second nature (MW183). However, this is precisely the kind of factorising move that McDowell criticises: separating truths about us into independent components corresponding to the aspects of likeness and difference. The commonality of non-conceptual content has simply been replaced in this move with the generic identity of first nature: conceptual content or second nature are specific differences respectively 'added' to the shared genus. On this conception the space of reason fails to extend all the way out; a metaphysical split re-emerges within the human being between first nature (nature) and second nature (reason). A particular problem at this point would appear to be the nature of the experience of pre-linguistic infants, as well as the very intelligibility of their acquiring a mother-tongue.

Heidegger, on the other hand, is quite explicit that his concept of experience makes our bodily kinship with animals 'scarcely conceivable' ${ }^{10}$ However, it is a requirement on any satisfactory conception of human experience that an intuitive sense of our kinship with other animals, the idea that we share nature with them, is accommodated. The problem is the following: how is it possible to articulate the sense we have that human beings belong within a natural world shared with other animals, without falling back into the traditional conception of what we share as something given? This has the shape of a genuine aporia. If nature is permeated with conceptual content then we 
overcome the dualism of reason and nature within the human being but at the expense of making unintelligible the intuition that we are beings who share nature with animals. If, on the other hand, we respond to the dilemma by positing a common, shared nature then the dualism between reason and nature once again reappears within us. What is needed is a re-worked conception of the form and content of human intuition that accommodates the sense that our receptivity belongs within the wider nature we share with other animals, without falling back into the idea of all animal species, including the human being, sharing a common, brute nature that is simply given.

\section{II}

Merleau-Ponty, by offering contra early Heidegger and McDowell a more radical 're-enchantment' of nature, outlines a conception of experience along these lines. Merleau-Ponty's conception of experience has two aspects - first, a more radical re-enchantment of second nature; the natural generality of the human being's life-world. This occurs in The Visible and the Invisible. The second aspect is a complementary radicalisation of the conception of animal nature apparent especially in the second course on the concept of nature given by Merleau-Ponty from 1957 to 1958. The Visible and the Invisible and the lectures on nature are therefore complementary works offering two sides of a single argument.

Like early Heidegger and McDowell, Merleau-Ponty suggests that the content we take in during perceptual experience is meaningful; that the perceived or visible is not given through the act of perception, but is the reason for that act. ${ }^{11}$ We find meaning already 'there' within the world of the visible; hence the claim that the visible is lined by the invisible, that the perceived has an invisible inner framework. This experience of invisible meaning or ideality within perception Merleau-Ponty calls an experience of the 'flesh' of things. However, perceptual experience of flesh does not simply entail taking on board conceptual content. The ideality or atmosphere we perceive is a kind of luminous field or "cohesion without concept"12 that gives to sensuous matter its axes, depths and dimensions rather than a categorical framework. Each fragment of Being has its own 'incarnate principle' or idea and these ideas or open vortexes fit in with one another to form one sole vortex, one flesh (ViIn 151). As such the kind of non-conceptual ideality Merleau-Ponty is concerned with bears resemblance to what Kant calls an aesthetic Idea. That is to say, a totality-of-significance the life and motion of whose internal relations exceed the linguistic expressions that would seek to determine the whole conceptually. ${ }^{13}$ Merleau-Ponty arguably then transfers and broadens the Kantian notion of an aesthetic Idea to the concept of world as such. The result of this aesthetic idea of world is a re-worked conception of Heideggerian facticity. The facticity of flesh, i.e. spirit or Geist in a Kantian register, gives 
meaning to the facts or units of articulated significance that constitute the objective aspects of our perceptible world.

Merleau-Ponty's re-worked conception of facticity includes a determination of the form, as well as the content, of our perceptual experience. The atmosphere or element that we perceptually take in appears meaningful because it is already ordered and organised into a particular form. MerleauPonty calls this form style: style brings coherence and structure to the 'aesthetic' totality of world. Style is not an a priori form supplied or given by the transcendental subject but is experienced as already out there in the world; an aesthetic form or pattern that we receive prior to empirical experience. Because things are disclosed from out of an aesthetic intuition of world they are not, consequently, as they are in Kant, appearances for us, hopelessly sundered from the in-itself. Style, in the sense in which Merleau-Ponty appears to use the concept, offers the kind of ontological constraint upon the ideality of the human subject that ultimately goes missing in early Heidegger and McDowell. For Heidegger and McDowell, the external manifold upon whose basis our operations of receptivity come into play is constituted by the already-given thought contents comprising the world into which we are thrown. As they say, Being is Dasein's understanding of Being (BT228); thought and Being are identical (MW 28f \& 33). The concept of style, on the other hand, determines our form of life as properly external to us, and thus as something that can genuinely be intuited. From out of the a priori, aesthetic intuition of style we see things as the things that they are. In a conception of sensibility that is no doubt profoundly influenced by later Heidegger, our eyes receive, Merleau-Ponty remarks, the 'gift of the visible'. ${ }^{14}$ As Heidegger might put it, there is style; style gives.

This constitutes Merleau-Ponty's radicalisation of early Heidegger and McDowell's conception of our second nature. The logos of the sensible world is aesthetically determined in both form and content. Style, the form of intuition that orders the atmosphere and element of the visible, is a gift to us from nature. The Being of flesh is essentially an idea but it is not metaphysically separate from the ontic matter that 'it gives'. Just as the musical theme is the atmosphere limited to these five notes, played in this order, so too the sensible idea that animates each actual particular is the atmosphere or dimension of 'this red', 'this green' (ViIn 151). Even if we abandon the flesh of the natural generality of the life-world for the flesh of language or culture, and so proceed from a theory of perception to a theory of linguistic meaning, this conception of experience still holds. Language still streams along the contours of sensible things and transfigures horizons it did not open (ViIn 153). Echoing remarks by Novalis and Wittgenstein, Merleau-Ponty claims that at the birth of concepts within a cultural field, there is present something like a second life, a power of nature evident in the sense language sustains by 
virtue of its own arrangement (ViIn 153). Thus, whereas early Heidegger and McDowell naturalised reason at the expense of rationalising nature, of making nature exhaustively cultural, Merleau-Ponty re-discovers a power of nature within culture. Nature is here radically re-enchanted in the sense that our second nature or form of life is animated, and so, contra McDowell and early Heidegger, determined as genuinely external to us. Language is no longer simply conceived as a repository for the conceptual repertoire of an inherited form of life. Our form of life gives, language 'speaks'.

The second course on the concept of nature, given by Merleau-Ponty in 1957-1958, should be seen in this light. In this course Merleau-Ponty transfers some of the ideas and categories he uses to describe the human life-world to the domain of what he calls 'animal culture'. The philosophical question at the centre of the course, Merleau-Ponty claims, echoing Heidegger, is the status of the totality of the animal organism (N145). Merleau-Ponty wants to avoid two possible responses to this question: either that the animal participates in a Platonic or Aristotelian essence hidden behind the observable phenomena or that the whole of the organism is simply the sum of mechanically related parts. The former position, he suggests, culminates in vitalism, whereby a positive principle, such as idea, essence or entelechy, doubles our conception of reality and then relies upon a vague notion of causality borrowed from mechanism in order to bridge the gap (N152). In response, Merleau-Ponty draws upon contemporary work in theoretical biology, and especially Uexküll, in order to form a position that retains a notion of the structural totality of an organism but without collapsing into the conception of a transcendent essence within which the animal participates. In doing so Merleau-Ponty's analysis goes beyond Heidegger in interesting ways.

Merleau-Ponty connects the idea of totality to the Uexküllian idea of a building plan: like any plan or design the structural relations within the totality possess meaning, but this meaning is not conceived as a positive presence or essence that can be specified apart from the physical matter that it organises. In itself the building plan denotes a negativity or absence - the word MerleauPonty repeatedly uses is 'dimension'. The dimensionality of the plan organises the different phases of the organism's spatial and temporal development into a meaningful whole, making the 'collective animal' composed of multiple functions into an 'ensemble'. This unity or hollowed-out design is not pregiven but rather emergent; it is a 'vital event' (N174) that surges up through the physical matter that it animates and regulates.

In order to illustrate the conception of totality, Merleau-Ponty compares it to a musical theme. The animal's existence realises the theme, without this realisation being a copy of a pre-existing model or a determinate telos the animal is directed towards: the unfurling of an Umwelt is more like a 'melody that is singing itself' (N173). The description of the musical nature of the 
animal's building plan plays the same role as the description of the musical character of the invisible flesh that clings to concrete things in the human experience. As Merleau-Ponty says in the lecture course on nature, once again, as in The Visible and the Invisible, citing Proust, melody is a Platonic idea that we cannot see separately (N174). Within this form of "naturalised Platonism", applicable to both the world of man and the environment of animal, we cannot separate the meaning, broadly speaking, from its mode of expression or concrete performance. Thus the theme of the animal's life constitutes the whole of the organism yet this is not to posit an ontologically separable and pre-existing essence in which the animal participates. Likewise, just as in a melody the last note is present in the first note without there being asymmetrical, causal relations between first and last, so too the later developmental phases of the organism are present at the beginning without being mere possibilities waiting to be realised.

The theme of the animal is made concrete in the emergence of an environment or milieu. The horizon of intelligibility constituting the spatially and temporally framed milieu is a priori: it emerges as a condition for the possibility of the perception and oriented action of the animal, organising and filtering the kinds of stimuli that the animal is 'open for' and able to 'relate itself to'. Beyond Heidegger's discussion, however, Merleau-Ponty proceeds to push the interpretation of the Uexküllian encircling ring in an "aesthetic" direction, bringing his analysis astonishingly close to the reading of Uexküll offered by Deleuze and Guattari in A Thousand Plateaus. Deleuze and Guattari's interpretation of Uexküll likewise focuses upon the idea of "nature as music". ${ }^{15}$ Interestingly, Deleuze and Guattari also specify the nature of the physical matter through which the totality surges forth in the production of a milieu: pure sensory qualities or sensibilia, such as colours, textures, odours and sounds. The material contents of these sensibilia become expressive when they are animated by the rhythmic force of the totality or 'refrain' that gathers them into an articulated multiplicity. The material contents that constitute the structure of the animal's milieu are in this sense self-organising, or, as Deleuze puts it, auto-objective.

This reading of Uexküll avoids the 'Kantian' metaphysics that Uexküll foisted upon his own scientific research: human reality is conceived as mere subjective appearance, alongside the phenomenal worlds of the lower and higher animals, whilst the objective, empirical world is conceived as an unknowable noumenon somehow possessing causal relations to these subjective appearances. ${ }^{16}$ On the contrary, the qualities that constitute the material structure of the animal's encircling ring are not mere projections from the animal-subject. In the rhythmic self-movement that animates colours, sounds and odours, matter becomes expressive, that is to say: sensation passes over into external materiality just as physical matter is, first and foremost, 
sensuously perceived. Sensations are not subjective coatings that the subject projects over the objects of experience: as spatially and temporally differentiated, self-moving marks they constitute the exterior, objective resistance of the horizon or 'ring' from out of which beings emerge. In other words, the beings an animal is 'open for' within its environment are constituted through a natural power of expression involving a faculty of receptivity on the part of the animal, rather than projection or construction. The rhythm of each discrete territory gives the external constraint from out of an experience of which the 'reality' or horizon of objectivity for the particular animal emerges. There is here a multiplicity of modes of the flesh: an invisible flesh of the animal's environment analogous to the flesh of the human world described in The Visible and the Invisible.

However, Merleau-Ponty insists that in the conception of the building plan as a self-organising rhythm, ontological value has been given back to the notion of species (N189). The concept of species is not defined by mere community of descent or organic form but is a 'slope' on which all animals of the species are placed (N189). This 'slope' is determined by the form of the milieu that expresses the building plan of a particular animal, the form itself specified in terms of the dynamic structure that unifies the sensibilia within an ensemble. The rhythmic form of life of an animal individuates the species to which it belongs: animals on the same 'slope' share the same overarching rhythm - allowing of course for individual variations on the theme. The animal does not produce the species-specific, objective milieu but rather is the realisation or concretion of it. Only on the basis of the design of its encircling ring can the animal relate perceptually and behaviourally to the territory within which it lives. However, the animal is not a passive product of an external rhythmic force subsisting independently of it. The objective milieu is only made concrete and realised in the active expression of the animal. Because of this, focusing on Portmann, Merleau-Ponty suggests that ornamentation should not be given an entirely functional explanation (N187f). Some animals may resemble their surroundings in colour and even texture in order to survive, but many organisms take on forms and colourings that complicate their existence and which have no obvious functional explanation. Indeed, Merleau-Ponty suggests, the sensuous marks or qualities converge as elements of an underlying design in order to allow the animal's body to emerge as a mode of expression. There are levels of expression corresponding to the lower and higher animals: the shell of a spiralled mollusc possesses an extensive richness mechanically produced by local acts of secretion, whilst the design of a zebra's skin possesses a signification because it is realised by the ensemble of a convergent process (N188).

A similar analysis is available in relation to instinctive behaviour. The emergence of matters of expression are not functions tied to subjective types 
of action such as aggressiveness, sexuality or flight but are existential forms of manifestation. In the higher animals, at least, expression entails the first appearance of animal culture: organisms - ensembles of meaning - show themselves to each other in a kind of gestural, purely sensuous language. Merleau-Ponty and Deleuze revealingly use the same concept to determine this kind of expressive behaviour: style. Each animal species possess a certain 'style of action' (N156). Here Merleau-Ponty explicitly transfers another focal category from his phenomenology of human nature to his analysis of animal life. Style names the structure of the whole, the Umwelt, which organises and regulates the animal's behaviour. As in human existence, style is not produced by the animal; the animal's endogenous initiative expresses style, just as the singer expresses a melody that sings itself or as a performer must 'dash on her bow' as she follows the sonata as it sings through her (N173f; ViIn 151). In both cases it is the sensible or musical idea that possesses the animal or the artist rather than the other way around. The concept of style is further linked by Merleau-Ponty and Deleuze to the ritual and ceremonial aspects of animal behaviour, the latter being fundamentally misunderstood if interpreted solely as mere preparations for functions such as copulation. The ceremony, for example, of the brown stage-maker, which lays down landmarks each morning by dropping leaves it has picked from the tree and inverting them so the paler side stands out against the dirt, serves to open up a ritual space of territorial expression. ${ }^{17}$ Developing some remarks of Lorenz, Merleau-Ponty suggests that in ceremonial activity the animal takes pleasure in performing the act itself, even if no object is actually present. The release of an inner tension within the animal, to which Heidegger also refers, is on this radicalised interpretation of Uexkull's ethology less a response to an external cause than a kind of musical resolution.

To draw things together, the problem to which Merleau-Ponty's later work responds is: how is it possible to satisfy our everyday intuition that we share something with other animals without falling back into the traditional, factorising conception of a given, common nature to which we 'add' reason. McDowell and early Heidegger overcome the metaphysical division within the human being between natural receptivity and rational spontaneity but at the expense of determining second nature as exhaustively conceptual. The metaphysical division reappears between human beings (reason) and other animals (nature). What is needed is a conception of commonality that does not collapse into a low-lying level of givenness. Yet it is precisely the beginning of a sketch of such a conception that Merleau-Ponty's radicalised re-enchantment of nature tentatively provides.

The solution appears to look something like this: Merleau-Ponty's conception of human and animal nature provides access to the crucial idea, not of species-essence, but of species-expression. A species has 'neither doors nor 
windows' in that it expresses a unique rhythm that marks and stretches open the objective territory within which it lives. This monadology, combining with a Spinozist revaluation of the concept of species, jettisons Leibniz's identification of substantiality with particularity. The world of each species is closed in upon itself: its walls draped in a dazzling, unique array of diverse colour-tapestries, sounds, textures and odours. Each species expresses life differently: the fly-world differs radically, from the ground up, from the world of the lizard and from the world of the crab. There is no common, given 'content' that these species share; nor does objective, empirical reality subsist behind these "subjective" worlds.

But there is something 'shared' here. The style of animal territories and the style of human worlds offer unique expressions of the "same": each participates in, shares, life. This is a dialectical resolution: life is not a common, given content; it is nothing that is. Rather, life gives. Rather than reverting to a traditional anthropology, the incipient plurality and radicalism entailed by McDowell's and Heidegger's separation of man and animal is at this moment forced through. Beyond Schellingian onto-theology, to which Uexküll turned in his later work, there is rhythm in the unfurling of the human world and in the artistic marking of the animal's territory. This idea represents a Kantian modulation of the Leibnizian monadology: following a pattern familiar from the Critique of Judgement, human and animal species express or repeat the same Geist differently. Each species, including the human being, receives and expresses the gift of life in a unique and irreducible form of life or milieu. The relation between human beings and animals is dark because, as Heidegger rightly understood, an abyss separates us. The world of man and the environment of the animal are different, from the ground up. There is nothing given which we can isolate and be said to share. Yet, as Merleau-Ponty insists and Heidegger concedes, there is a strange kinship between man and animals. Merleau-Ponty synthesises the element of truth contained in these seemingly irreconcilable insights into difference and commonality: the modes of flesh of human and animal nature receive and repeat differently the activity or spontaneity of life as 'it gives' itself.

Natural selection in this sense acts on the variety of elements within the totality of the building plan - not just genes but also on all the environmental resources, landscape features and traditional community structures that make up the entire developmental process or life-cycle of the animal. Selection understood as the differential replication of life-cycles acts on the forms of order already present in the emergence of a milieu. These sources of living order, as a particular strain of developmental biology has always insisted, cannot be reduced to physical or chemical processes. Selection of selforganising life-cycles entails the establishment of motifs and refrains in counterpoint to others, but also the collapse of worlds that fail to improvise in 
the 'machinic opera' of nature. To borrow Uexküll's metaphor: if the worlds of men and animals are like soap bubbles, then the fact of selection means that many of these bubbles are continually popping out of existence. The capacity for expression, in this case, is a criterion for fitness value.

With the notion of the human and animal expression of the 'same' the possibility of a reconceived faculty of reception arises. Whereas human receptivity for Heidegger and McDowell involves the passive actualisation of conceptual capacities, and thus appears divorced from anything intelligibly natural, the aesthetic mode of receptivity shared by humans and animals is open to the natural power of rhythm. In the act or spontaneity of each mode of species-expression the sensus communis is actualised in a unique way. In other words, the receptivity associated with the sensus communis is not a freefloating capacity ontologically separable from spontaneity or activity. As Merleau-Ponty implies, the concept of species-expression entails degrees and gradations of a metaphysically unified 'spontaneous receptivity' within the allembracing sphere of life. This conception retains the crucial difference of the human being from other animals. Although animals are expressive creatures and thus to an extent 'inspired', nonetheless only in man does inspiration entail giving thanks to life for the gift of life and thus realising the gift by returning it to life. No other animal can return the gift. This distinctive mark of the human being is the highest form of animal expression: freely and actively to re-shape and modulate the (second) nature that gives to us the capacity to think. In a Heideggerian variation on what is essentially an Aristotelian thought, the human activity which most of all fulfils the reception and return of the gift of Being is thinking, the free exercise of reason embodied in the creation of a philosophical work. As Merleau-Ponty remarks, art and philosophy are not fabrications in the universe of culture but contact with Being (or presumably nature) precisely as creations: 'Being is what requires creation of us to experience it' (ViIn 197).

Finally, by installing a conception of aesthetic intuition at the centre of a shared sensus communis, Merleau-Ponty opens up the possibility of, as Heidegger puts it, 'transposing' ourselves into the inner lives of other animals (FCM201ff). McDowell and Heidegger quite rightly criticise the idea that we can gain access to the inner life of an animal by contemplating a reproduction of its retinal image and thereby picturing the kind of raw information the animal takes in through its sense organs. We are therefore barred from asking the theoretically framed 'what is it like to be a...?' question. Nor, despite Uexküll's efforts, can an objective study of the anatomical structure of the animal's body be plausibly said to yield an insight into the subjective, inner world of the organism. Yet conceived as an expression of life we nonetheless can 'go-along-with' the experience of another animal: though we always ultimately remain on our side, there is the more modest possibility of access 
to the inner being of other animals whose physical shape approximates our own. We can do this not through scientific observation but in the kinds of action that re-express the animal's form of life, in an inspired repetition of its bodily posture, gesture and forms of movement. Only action that is originarily expressive can be re-expressed - and not merely copied. The sphere of bodily action and behaviour, framed in terms of the concept of style, offers a point of access into the aesthetically structured relations constituting the animal's inner and outer world. It is precisely this 'going-along-with' the experience of an animal, a becoming-animal which lets the animal remain as animal, that is evident, for example, in the world of the cave-artist, shaman and tracker. Tracking is literally a form of art; to track is to be inspired, to enter into and express the spirit of the particular animal species in order to 'go along with' the member of the species one is tracking. The tracker, not the comparative anatomist, offers the point of access to animal life other than our own. But we can intelligibly 'go along with' other animals in this way only because the nature of the animal and our own second nature are both conceived as expressions of life, different repetitions of the same.

To conclude, the conception of nature Merleau-Ponty offers in his later work metaphysically grounds the sense of kinship between man and animal exhibited in expressive forms of behaviour such as tracking and displayed in the variety of rituals and festive rites comprising the life of what Heidegger calls primitive Dasein. Whilst the conception of experience offered by early Heidegger and McDowell fails to accommodate this archaic sense of kinship, Merleau-Ponty's conception of experience does just this; it expresses a thought captured many centuries earlier by St. Augustine - all things participate in the song of the cosmos.

\section{References}

1. Merleau-Ponty, Nature: Course Notes from the Collège de France, trans. R. Vallier (Illinois: Northwestern University Press, 2003); from now on referred to as $\mathrm{N}$ in the Text.

2. Heidegger, 'Letter on Humanism', Pathmarks, ed. W. McNeil (Cambridge: Cambridge University Press 1998) pp 244-7

3. Heidegger, Being and Time, (Oxford: Blackwell 1995) p. 74, from now on referred to as BT in the text.

4. McDowell, Mind and World, (Massachusetts: Harvard University Press, 1998) p. 108; from now on referred to as MW in the text.

5. Heidegger, The Fundamental Concepts of Metaphysics, trans. W. McNeill and N. Walker (Indianapolis: Indiana University Press, 1995) p. 176, from now on referred to as FCM in the text).

6. On this see P. Griffiths and R. Gray, 'Developmental Systems and Evolutionary Explanation', Journal of Philosophy vol. XCI, no. 6 June 1994.

7. Uexküll, J. von, Theoretical Biology, trans. D. L. Mackinnon (London: Kegan Paul, 1926) p. XV

8. McDowell, J. 'The Content of Perceptual Experience', in Mind, Value and Reality (Massachusetts: Harvard University Press, 1998) p. 346-7.

9. See also: Heidegger, 'Letter on Humanism', p. 248. 
10. Heidegger, 'Letter on Humanism', p. 248

11. This an uncontroversial point. See for example, Carmen and Hansen, 'Introduction', M. Wrathall, 'Motives, Reasons and Causes' in The Cambridge Companion to Merleau-Ponty, ed Carmen and Hansen (Cambridge, Cambridge University Press, 2004)

12. Merleau-Ponty, The Visible and the Invisible, trans. A. Lingis (Evanston, Northwestern University Press, 1968) p. 152; from now on referred to as ViIn in the text.

13. Kant, Critique of Judgement, trans. Pluhar (Indianapolis, Hackett Publishing, 1987) p. 185.

14. Merleau-Ponty, 'Eye and Mind', in Merleau-Ponty Aesthetics Reader ed. Galen Johnson (Northwestern University Press, 1993) p. 127.

15. Deleuze and Guattari, A Thousand Plateaus, trans. Massumi (London: Continuum 2002) p. 314

16. Uexküll, J. von, Theoretical Biology, trans. D. L. Mackinnon (London: Kegan Paul 1926) p. $x v$

17. Deleuze and Guattari, A Thousand Plateaus, p. 315 